\title{
Molecular characterization of an analphoid supernumerary marker chromosome derived from $18 q 22.1 \rightarrow$ qter in prenatal diagnosis: a case report
}

\author{
Vincenzo Altieri ${ }^{1 \dagger}$, Oronzo Capozzi ${ }^{2 \dagger}$, Maria Cristina Marzano ${ }^{3}$, Oriana Catapano ${ }^{4}$, Immacolata Di Biase ${ }^{4}$,
} Mariano Rocchi ${ }^{2^{*}}$ and Giuliana De Tollis ${ }^{1 *}$

\begin{abstract}
Background: Small supernumerary marker chromosomes (SSMC) occur in $0.072 \%$ of unselected cases of prenatal diagnoses, and their molecular cytogenetic characterization is required to establish a reliable karyotype-phenotype correlation. A small group of SSMC are C-band-negative and devoid of alpha-satellite DNA. We report the molecular cytogenetic characterization of a de novo analphoid SSMC derived from 18q22.1 $\rightarrow$ qter in cultured amniocytes.

Results: We identified an analphoid SSMC in cultured amniocytes during a prenatal diagnosis performed because of advanced maternal age. GTG-banding revealed an SSMC in all metaphases. FISH experiments with a probe specific for the chromosome 18 centromere, and C-banding revealed neither alphoid sequences nor C-banding-positive satellite DNA thereby suggesting the presence of a neocentromere. To characterize the marker in greater detail, we carried out additional FISH experiments with a set of appropriate BAC clones. The pattern of the FISH signals indicated a symmetrical organization of the marker, the breakpoint likely representing the centromere of an inverted duplicated chromosome that results in tetrasomy of 18q22.1 $\rightarrow$ qter. The karyotype after molecular cytogenetic investigations was interpreted as follows:

47,XY,+inv dup (18)(qter $\rightarrow$ q22.1::q22.1 $\rightarrow$ neo $\rightarrow$ qter)
\end{abstract}

Conclusion: Our case is the first report, in the prenatal diagnosis setting, of a de novo analphoid marker chromosome originating from the long arm of chromosome 18, and the second report of a neocentromere formation at 18q22.1.

Keywords: Small supernumerary marker chromosomes, Neocentromere, Prenatal diagnosis, FISH analysis

\section{Background}

Small supernumerary marker chromosomes (sSMC) are structurally abnormal chromosomes that cannot be identified by conventional banding pattern analysis [1]. They are usually characterized by molecular cytogenetic techniques [2]. De novo sSMC are not rarely encountered during prenatal diagnosis. In fact, they occur in $0.072 \%$ of unselected cases of prenatal diagnoses [3]. Their frequency increases with advanced maternal age [4].

Most de novo sSMC originate from acrocentric chromosomes, and approximately $50 \%$ of them originate from the centromeric region of chromosome 15 [5].

\footnotetext{
*Correspondence: mariano.rocchi@uniba.it; genetica@asInapoli1centro.it ${ }^{\dagger}$ Equal contributors

${ }^{2}$ Department of Biology, University of Bari, Bari, Italy

'Department of Genetics, ASL Napoli 1 Centro, Napoli, Italy

Full list of author information is available at the end of the article
}

Karyotype-phenotype correlations are well established in the latter cases [6]. The karyotype-phenotype correlation of the remaining SSMC is generally unknown, and the phenotypes range from normal to dysmorphic features and/or developmental delay, depending on the chromosomal region involved, the level of mosaicism, and tissue distribution of the sSMC [7]. Thus, it is important to characterize new sSMC identified during prenatal diagnosis in order to establish the clinical outcome.

A small group of markers have an analphoid, C-bandnegative centromere but they are substantially stable in vivo and in vitro, which suggests the formation of a newly derived functional centromere, called "neocentromere" $[8,9]$. We report the finding of a de novo analphoid sSMC derived from the long arm of chromosome 18 in a case of prenatal diagnosis, and its characterization using

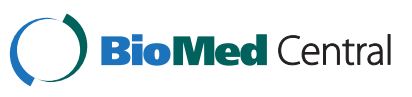

(c) 2014 Altieri et al.; licensee BioMed Central Ltd. This is an Open Access article distributed under the terms of the Creative Commons Attribution License (http://creativecommons.org/licenses/by/4.0), which permits unrestricted use, distribution, and reproduction in any medium, provided the original work is properly credited. The Creative Commons Public Domain Dedication waiver (http://creativecommons.org/publicdomain/zero/1.0/) applies to the data made available in this article, unless otherwise stated. 
fluorescence in situ hybridization (FISH) studies. To our knowledge, this is the second report of the formation of a neocentromere at 18q22.1 [10].

\section{Case presentation}

A 44-year-old primigravida woman underwent genetic counseling and amniocentesis at 18 weeks of gestation because of advanced maternal age. The woman and her husband were healthy and non-consanguineous. There was no family history of congenital malformations. She denied exposure to alcohol, tobacco smoke, irradiation or infectious diseases during pregnancy. The amniotic fluid alpha-fetoprotein level was normal. Rapid screening for aneuploidy in uncultured amniocytes using the BACs-on-Beads ${ }^{\text {Th }}$ assay (PerkinElmer Wallac OY, Turku, Finland) did not reveal chromosome anomalies, and fetal gender was male. G-banding cytogenetic analysis, performed on 15 colonies in primary amniocyte cultures, revealed an sSMC about the same size as a group G chromosome in all cells. The fetal karyotype was: 47, $\mathrm{XY}+$ +mar (Figure 1). The marker was negative for $\mathrm{C}$-banding (Figure 2). The origin and architecture of the sSMC were unclear.

Chromosome analysis on the two phenotypically normal parents showed normal karyotypes in all the 30 cells examined. Ultrasonography carried out during the 21st week of pregnancy revealed normal fetal growth (30th centile), and nasal bone hypoplasia, which is a soft marker of fetal aneuploidy. The parents were counseled and chose to terminate the pregnancy. A postmortem examination of the fetus revealed no external dysmorphic features.

Amniocytes were subcultured for further analyses. The marker dropped rapidly to 50\%. Multiplex FISH with spectral karyotyping identified the marker as a derivative of chromosome 18 (Figure 3A). This was confirmed using a whole chromosome painting probe specific for chromosome 18 (Figure 3B). Partial chromosome painting probes specific for the long and the short arms of chromosome 18 indicated that the marker derived from the long arm of chromosome 18 (Figure 3C). The multicolor probe panel used to reveal alpha satellite sequences failed to show signals on the marker (Figure 3D). Additionally, we amplified total human DNA with alpha-satellite primers derived from the conserved regions of human alpha satellite sequences [11], and used the amplified product as a probe in FISH experiments. The procedure is able to detect all human centromeres, but it failed to detect any signal on the marker [11]. We therefore assumed that the marker chromosome contained a newly formed centromere (i.e., a neocentromere).

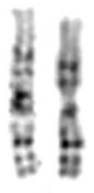

1

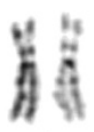

6

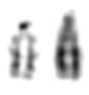

13

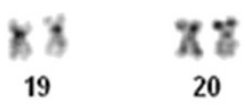

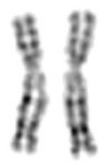

2

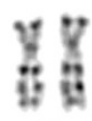

7

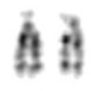

14

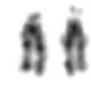

15

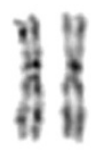

3

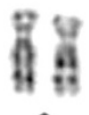

8

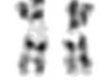

9

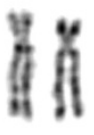

4

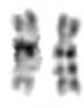

10

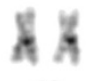

16
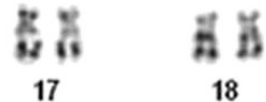

18

1 G-banded karyotype showing the marker chromosome. 


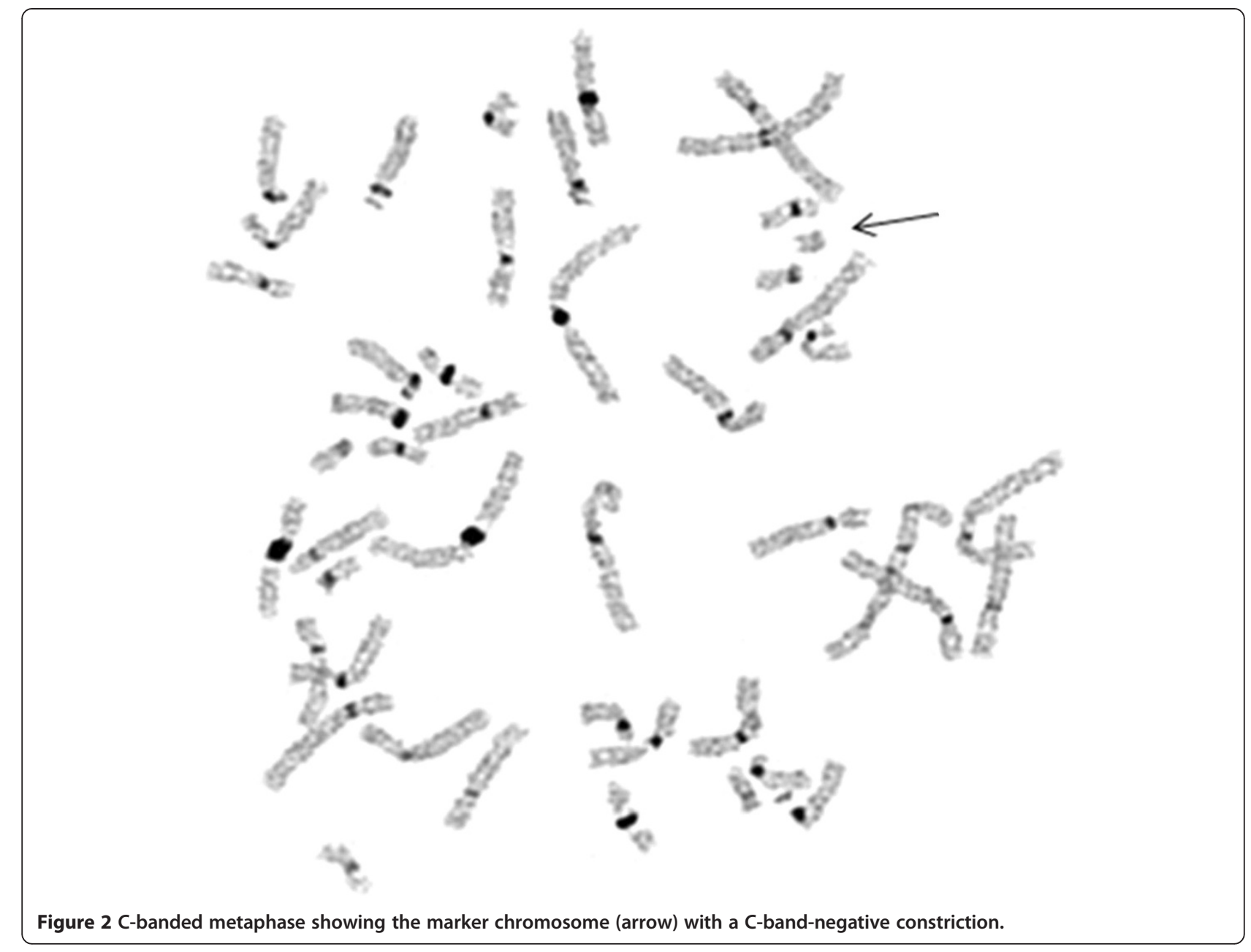

We performed a quantitative fluorescence-PCR analysis on secondary cultured amniocytes by amplifying 24 loci on chromosomes X, Y, 13, 18 and 21. The electropherograms revealed a male genotype with a normal pattern for chromosomes 13 and 21. In the case of chromosome 18, the informative microsatellite markers D18S391, D18S1002, D18S535, and D18S858 (18pter $\rightarrow 18 q 21.31$ ) showed two balanced peaks, revealing a normal heterozygote pattern, while the D18S386 marker (18q22.1) showed two unbalanced peaks (peak area ratio 1:2) (Figure 4), suggesting that the markers derived from the distal end of the long arm of chromosome 18.

We used appropriate BAC clones spanning the $18 \mathrm{q} 21.1 \rightarrow 18 \mathrm{qter}$ chromosomal region to characterize the extension and organization of the marker in greater detail. Examples of FISH experiments are shown in Figure 5. The exact position of each $\mathrm{BAC}$ on the GRCh37/hg19 assembly was identified using the UCSC genome browser (Table 1). The last negative and the first positive BAC clones, RP11-316J22 and RP11775G23, respectively, defined the breakpoint as lying on, or very close to, the chr18:63,292,882-63,296,150 interval (3,268 bp), at 18q22.1. A FISH experiment with a probe specific for the telomeric sequences revealed a clear signal at both ends of the marker (Figure 5T). The pattern of the FISH signals (Figure 5) indicated a symmetrical organization of the marker, the breakpoint likely representing the centromere of an inverted duplicated chromosome. The latter notion is supported by the finding that CENP-A, playing a key role in centromere specification, is rapidly recruited to double-strand breaks [12].

Based on the FISH results we interpreted the karyotype as:

$$
\text { 47,XY,+inv dup (18) }(\mathrm{qter} \rightarrow \mathrm{q} 22.1:: \mathrm{q} 22.1 \rightarrow \text { neo } \rightarrow \text { qter })
$$

\section{Conclusions}

Supernumerary marker chromosomes are a major clinical problem in prenatal genetic diagnosis and counseling. Detailed characterization of the marker chromosome is required to establish a reliable genotype-phenotype correlation, in the absence of which prognostic counseling can only be based on theoretical data. We report the prenatal molecular cytogenetic characterization of an analphoid 

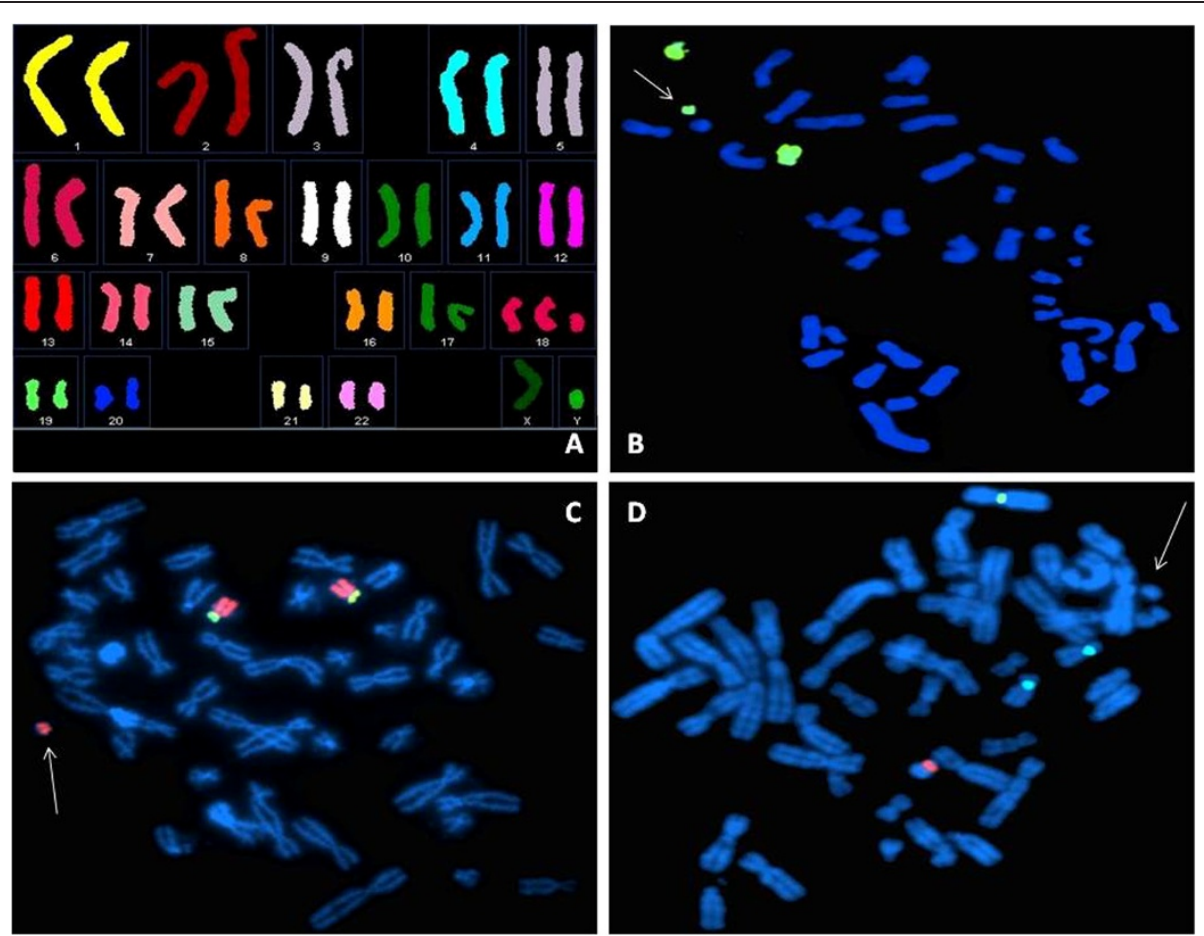

Figure 3 Molecular cytogenetic characterization of the marker chromosome. Arrows indicate the marker chromosome. (A) Spectral karyotyping. (B) Whole chromosome paint 18 green. (C) chromosome 18 arm-specific painting, 18p green/18q red. (D) Multicolor DNA Probe Kit CEP 18 aqua/X green/Y orange.

sSMC consisting of an inverted duplication of the distal region of chromosome $18 \mathrm{q}$ that results in tetrasomy of $18 \mathrm{q} 22.1 \rightarrow$ qter. In the only other previous report of an apparently neocentric marker of chromosome 18 , the authors describe a stable analphoid marker of chromosome
18 in a child with dysmorphic features and mild mental retardation [13]. However, the marker was not characterized in detail.

The severity of the phenotype in sSMC cases could depend on the chromosomal region involved in the

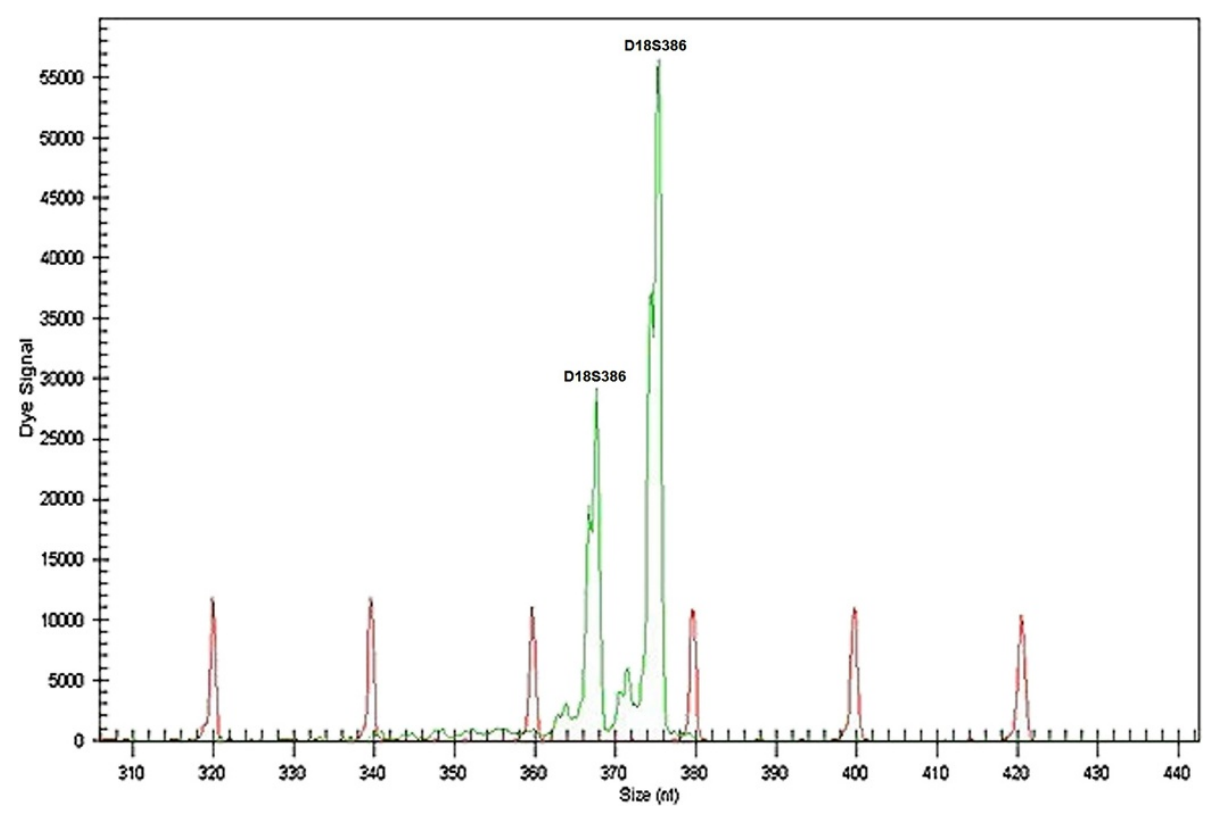

Figure 4 Electropherogram of the unbalanced marker D18S386 on chromosome 18. 

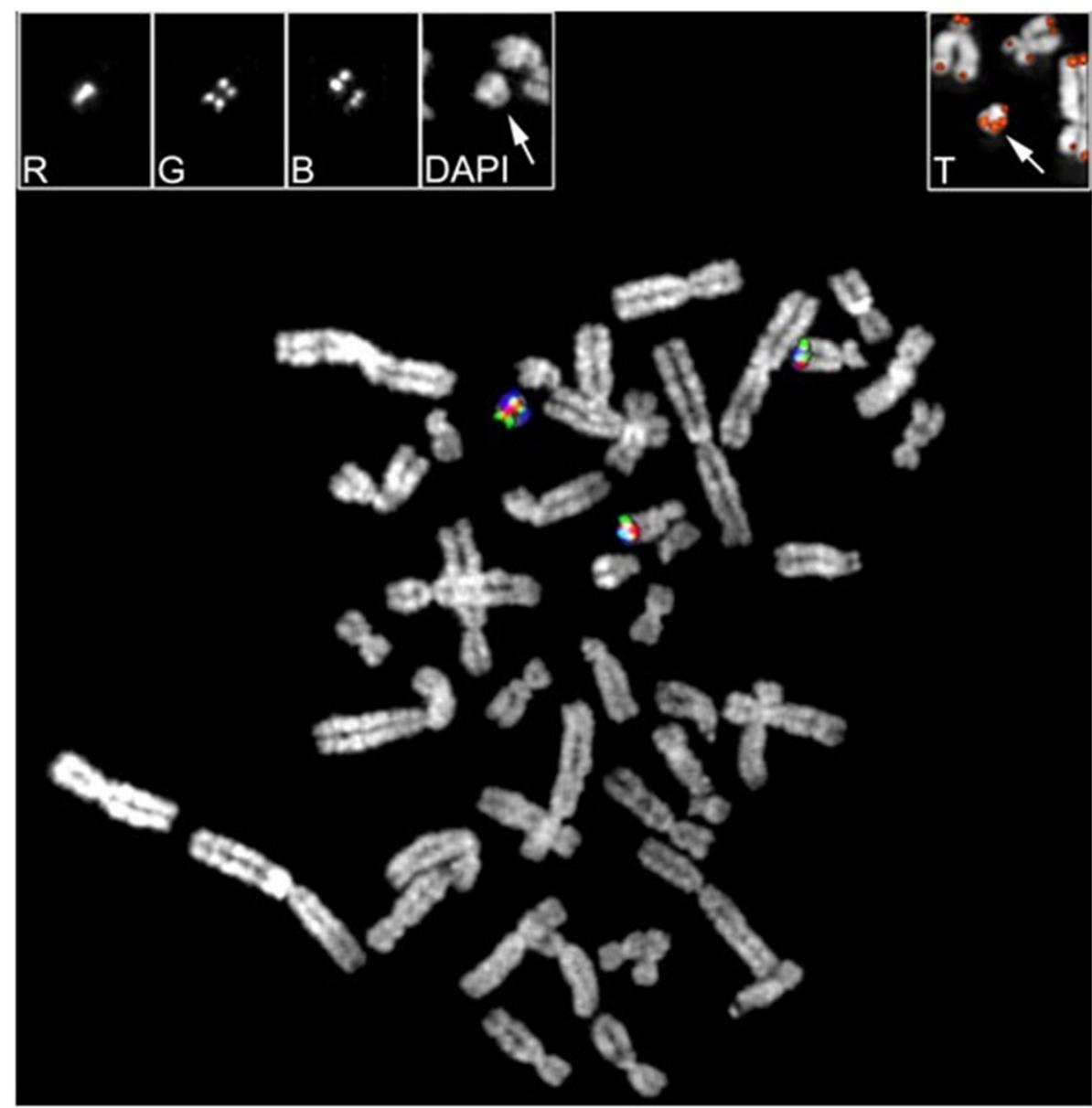

Figure 5 Co-hybridization experiments using BACs RP11-24617 (red; centromeric), RP11-177C10 (green) and RP11-715C4 (blue; telomeric). Their mapping position on chromosome 18 is reported in Table 1. For clarity, the original black and white FISH signals for RP11-24617 (R), RP11-177C10 (G), RP11-715C4 (B), and DAPI are reported separately in the upper left boxes. The partial metaphase in the upper right box shows the telomeric FISH signals of the marker (arrowed).

Table 1 Name, location and FISH results of the BAC clones used in this study

\begin{tabular}{llll}
\hline BAC name & hg19 position & Chr band & $\begin{array}{l}\text { On } \\
\text { marker }\end{array}$ \\
\hline RP11-634P8 & chr18:47,976,335-48,168,694 & $18 q 21.1-18 q 21.2$ & No \\
RP11-153B11 & chr18:54,667,206-54,826,907 & $18 q 21.31$ & No \\
RP11-299P2 & chr18:60,776,519-60,923,180 & $18 q 21.33$ & No \\
RP11-933E2 & chr18:61,040,533-61,226,049 & $18 q 21.33$ & No \\
RP11-316J22 & chr18:63,126,423-63,292,882 & $18 q 22.1$ & No \\
Breakpoint & & & \\
RP11-775G23 & chr18:63,296,150-63,472,757 & $18 q 22.1$ & Yes \\
RP11-164016 & chr18:63,505,969-63,674,351 & $18 q 22.1$ & Yes \\
RP11-1069K2 & chr18:63,677,806-63,866,636 & $18 q 22.1$ & Yes \\
RP11-24617 & chr18:64,155,311-64,339,348 & $18 q 22.1$ & Yes \\
RP11-177C10 & chr18:69,512,241-69,673,238 & $18 q 22.3$ & Yes \\
RP11-715C4 & chr18:76,390,026-76,578,392 & $18 q 23$ & Yes \\
\hline
\end{tabular}

aneuploidy, the number of copies of the region, and the stability of the acentric fragment [14,15]. In our case, the couple decided to terminate the pregnancy. The fetus was examined and did not have any apparent anatomical anomalies. However, the high stability of the neocentric sSMC, present in all cultured primary amniocytes, and the euchromatic content suggested a high risk of severe psychomotor retardation. Furthermore, correlative analysis suggested that duplication of $18 \mathrm{q} 22.1 \rightarrow 18 \mathrm{qter}$ is associated with severe mental retardation $[16,17]$.

Analphoid sSMC are rare but interesting because their survival and stability depend on the seeding of a new centromere known as "neocentromere" [8,9]. Since the pivotal report of Voullaire et al. [18], approximately 120 human neocentromeres, deriving from 20 different autosomal chromosomes as well as from $\mathrm{X}$ and $\mathrm{Y}$ sex chromosomes, have been described [19]. Most of these neocentromeres are located on marker chromosomes 
derived from inverted duplications of terminal chromosomal regions, and result in trisomy/tetrasomy of the region $[9,20]$. The known human neocentromeres cluster in some chromosomal regions [9]. In one case (15q), the cluster region corresponds to the region where an ancestral centromere was inactivated during evolution [21]. In our case, the neocentromere seeding region corresponds, at cytogenetic level, to the same chromosomal 18 q22.1 band in which a neocentromere was previously described [10]. In the latter prenatal diagnosis, the centromere repositioned along chromosome 18 that was otherwise normal. It would be interesting to investigate whether or not the same region, at sequence level, underlies both neocentromeres. However, the lack of sequence data in the two cases preclude further investigation. Interestingly, three neocentromeres seeded at $13 q 32$ were found to be seeded in different DNA domains [22].

\section{Materials and methods Chromosome analysis}

Chromosome analysis was carried out on metaphase cells derived from amniotic fluid cells according to standard procedures. Twenty metaphase cells from 15 colonies in primary cultures were analyzed with G-banding and $\mathrm{C}$-banding. Chromosome preparations of peripheral blood lymphocytes from the parents were subjected to G-banding, and 30 metaphase spreads were analyzed. Karyotypes are described according to the International System for Human Cytogenetic Nomenclature (ISCN 2013).

\section{Quantitative fluorescent polymerase chain reaction}

DNA from secondary cultured amniocytes was extracted by means of a conventional salting-out protocol. Quantitative fluorescent-PCR was performed with a home-made kit that analyzed, in two multiplex reactions, the amelogenin and SRY genes, and 22 microsatellite markers of chromosomes X, Y, 13, 18 and 21. Capillary electrophoresis was performed with a CEQ 8000 sequencer (Beckman Coulter).

\section{Fluorescence in situ hybridization analysis}

We used diverse FISH approaches, namely, multiplex FISH with the Spectral Karyotyping Assay ${ }^{\text {max }}$ (Applied Spectral Imaging Ltd., Migdal Ha'Emek, Israel); a whole chromosome painting probe specific for chromosome 18 (WCP18- Applied Spectral Imaging Ltd., Migdal Ha'Emek, Israel); a partial chromosome paint specific for the long and the short arms of chromosome 18 (MetaSystems, Altlussheim, Germany); a mixture of probes for the $\mathrm{X}$ chromosome centromere (DXZ1) and the Y chromosome centromere (DYZ3) (AneuVysion CEP 18/X/Y-alpha satellite; Abbott Molecular Inc., Des Plaines, IL,USA), and a telomere peptide nucleic acids probe (Telomere PNA FISH kit/Cy3; Dako, Denmark). Each FISH procedure was performed according to the manufacturer's instructions. DNA from BAC clones was extracted, labeled, and hybridized according to Lichter et al. [23] with minor modifications.

\section{Ethical approval and consent}

These studies were performed on anonymized samples received in the clinical laboratory and thus were exempt from the requirement for consent according to the Western Institutional Review Board. However, written informed consent was obtained from the parents for publication of this case report. A copy of the written consent is available for review by the Editor-in-Chief of this journal.

\section{Competing interests}

The authors declare that they have no competing interests.

\section{Authors' contributions}

VA First co-author, performed preliminary FISH analyses and drafted the manuscript. OC First co-author, performed BAC FISH analyses. CM provided clinical information and performed the cytogenetic analyses. OC and IDB carried out the QF-PCR analysis. MR Corresponding author, involved in drafting the manuscript and revising it critically for important intellectual content. GDT Corresponding author, helped to draft the manuscript. All authors read and approved the final manuscript.

\section{Acknowledgements}

This work was supported by PRIN 2012 to MR. The authors thank Jean Ann Gilder (Scientific Communication Srl., Naples, Italy) for editing the manuscript.

\section{Author details}

${ }^{1}$ Department of Genetics, ASL Napoli 1 Centro, Napoli, Italy. ${ }^{2}$ Department of Biology, University of Bari, Bari, Italy. ${ }^{3}$ Diagnostic Service Srl, Casoria, Napoli, Italy. ${ }^{4}$ MeriGen Research Srl., Napoli, Italy.

Received: 28 August 2014 Accepted: 6 October 2014

Published online: 22 October 2014

\section{References}

1. Shaffer LG, McGowan-Jordan J, Schmid M (Eds): ISCN 2013: An International System for Human Cytogenetic Nomenclature. Basel: S. Karger; 2013.

2. Liehr T, Claussen U, Starke H: Small supernumerary marker chromosomes (sSMC) in humans. Cytogenet Genome Res 2004, 107:55-67.

3. Malvestiti F, De Toffol S, Grimi B, Chinetti S, Marcato L, Agrati C, Di Meco AM, Frascoli G, Trotta A, Malvestiti B, Ruggeri A, Dulcetti F, Maggi F, Simon $G$, Grati FR: De novo small supernumerary marker chromosomes detected on 143,000 consecutive prenatal diagnoses: chromosomal distribution, frequencies and characterization combining molecular cytogenetics approaches. Prenat Diagn 2014, 34:460-468.

4. Hook EB: Chromosome abnormalities and spontaneous fetal death following amniocentesis. Further data and associations with maternal age. Am J Hum Genet 1983, 35:110-116.

5. Crolla JA, Harvey JF, Sitch FL, Dennis NR: Supernumerary marker 15 chromosomes: a clinical, molecular and FISH approach to diagnosis and prognosis. Hum Genet 1995, 95:161-170.

6. Crolla JA: FISH and molecular studies of autosomal supernumerary marker chromosomes excluding those derived from chromosome 15: II. Review of the literature. Am J Med Genet 1998, 75:367-381.

7. Liehr T, Mrasek K, Weise A, Dufke A, Rodriguez L, Martinez Guardia N, Sanchis A, Vermeesch JR, Ramel C, Polityko A, Haas OA, Anderson J, Claussen U, von Eggeling F, Starke H: Small supernumerary marker chromosomes-progress towards a genotype-phenotype correlation. Cytogenet Genome Res 2006, 112:23-34. 
8. Choo KH: Centromere DNA dynamics: latent centromeres and neocentromere formation. Am J Hum Genet 1997, 61:1225-1233.

9. Marshall OJ, Chueh AC, Wong LH, Choo KH: Neocentromeres: new insights into centromere structure, disease development, and karyotype evolution. Am J Hum Genet 2008, 82:261-282.

10. Klein E, Rocchi M, Ovens-Raeder A, Kosyakova N, Weise A, Ziegler M, Meins M, Morlot S, Fischer W, Volleth M, Polityko A, Mackie Ogilvie C, Kraus C, Liehr T: Five novel locations of neocentromeres in human: 18q22.1, xq27.1 27.2, acro p13, acro p12, and heterochromatin of unknown origin. Cytogenet Genome Res 2012, 136:163-166.

11. Terkelsen C, Koch J, Kolvraa S, Hindkjaer J, Pedersen S, Bolund L: Repeated primed in situ labeling: formation and labeling of specific DNA sequences in chromosomes and nuclei. Cytogenet Cell Genet 1993, 63:235-237

12. Zeitlin SG, Baker NM, Chapados BR, Soutoglou E, Wang JY, Berns MW, Cleveland DW: Double-strand DNA breaks recruit the centromeric histone CENP-A. Proc Natl Acad Sci U S A 2009, 106:15762-15767.

13. Rauch A, Pfeiffer RA, Trautmann U, Liehr T, Rott HD, Ulmer R: A study of ten small supernumerary (marker) chromosomes identified by fluorescence in situ hybridization (FISH). Clin Genet 1992, 42:84-90.

14. Warburton PE: Chromosomal dynamics of human neocentromere formation. Chromosome Res 2004, 12:617-626.

15. Burrack LS, Berman J: Neocentromeres and epigenetically inherited features of centromeres. Chromosome Res 2012, 20:607-619.

16. Koide K, Slonim DK, Johnson KL, Tantravahi U, Cowan JM, Bianchi DW: Transcriptomic analysis of cell-free fetal RNA suggests a specific molecular phenotype in trisomy 18. Human Genet 2011, 129:295-305.

17. Boghosian-Sell L, Mewar R, Harrison W, Shapiro RM, Zackai EH, Carey J, Davis-Keppen L, Hudgins L, Overhauser J: Molecular mapping of the Edwards syndrome phenotype to two noncontiguous regions on chromosome 18. Am J Hum Genet 1994, 55:476-483.

18. Voullaire LE, Slater HR, Petrovic V, Choo KH: A functional marker centromere with no detectable alpha-satellite, satellite III, or CENP-B protein: activation of a latent centromere? Am J Hum Genet 1993, 52:1153-1163.

19. Liehr T: Small supernumerary marker chromosomes (SSMC). [http://ssmc-tl. com/chromosome-18.html] (accessed 23/05/2014).

20. Amor DJ, Choo KH: Neocentromeres: role in human disease, evolution, and centromere study. Am J Hum Genet 2002, 71:695-714.

21. Ventura M, Mudge JM, Palumbo V, Burn S, Blennow E, Pierluigi M, Giorda R, Zuffardi O, Archidiacono N, Jackson MS, Rocchi M: Neocentromeres in 15q24-26 map to duplicons which flanked an ancestral centromere in 15q25. Genome Res 2003, 13:2059-2068.

22. Alonso A, Mahmood R, Li S, Cheung F, Yoda K, Warburton PE: Genomic microarray analysis reveals distinct locations for the CENP-A binding domains in three human chromosome $13 \mathrm{q} 32$ neocentromeres. Hum Mol Genet 2003, 12:2711-2721.

23. Lichter P, Tang CJ, Call K, Hermanson G, Evans GA, Housman D, Ward DC: High resolution mapping of human chromosomes 11 by in situ hybridization with cosmid clones. Science 1990, 247:64-69.

doi:10.1186/s13039-014-0069-4

Cite this article as: Altieri et al:: Molecular characterization of an analphoid supernumerary marker chromosome derived from 18q22.1 $\rightarrow$ qter in prenatal diagnosis: a case report. Molecular Cytogenetics 2014 7:69.

\section{Submit your next manuscript to BioMed Central and take full advantage of:}

- Convenient online submission

- Thorough peer review

- No space constraints or color figure charges

- Immediate publication on acceptance

- Inclusion in PubMed, CAS, Scopus and Google Scholar

- Research which is freely available for redistribution

Submit your manuscript at www.biomedcentral.com/submit

C Biomed Central 